\title{
A INTEGRAÇÃO DOS SISTEMAS STOP \& START E AQUECIMENTO DE COMBUSTÍVEL
}

\author{
Adriano Cardon Castro \\ Evaldir Negrelli \\ Renault do Brasil \\ adriano.castro@ renault.com, evaldir.negreli@ renault.com
}

\section{RESUMO}

No mundo automotivo, as regulamentações governamentais procuram atender as necessidades da sociedade quanto à segurança veicular (passiva e ativa), emissões de poluentes e ruídos, entre outras. Para promover a sustentabilidade e competitividade, o governo brasileiro lançou em dezembro de 2012 o programa Inovar-Auto, o qual estabelece uma de serie de ações industriais e desenvolvimento local, para a atualização de motores e veículos.

Um dos pilares deste programa é a eficiência energética, que pode ser melhorada através de diferentes opções de produtos. A introdução destas novas tecnologias, como motores mais econômicos, sistemas eletrônicos (como Stop \& Start, sistemas híbridos de recuperação de energia) e redução de peso, compõem estratégias próprias de cada montadora para responder às exigências governamentais.

Já no mercado brasileiro, devido à necessidade de ter motores que possam trabalhar com misturas de combustíveis de etanol e gasolina, várias adaptações de componentes são requeridas, como por exemplo, um sistema de partida a frio.

Este trabalho tem como objetivo descrever o sistema Stop \& Start, seus componentes e interfaces e o funcionamento deste com sistema de aquecimento de combustível, mostrando a complexidade de integração, as diferentes situações críticas e principais validações necessárias.

Ao final, serão apresentadas as futuras evoluções necessárias para que estes sistemas sejam utilizados no mercado local mantendo a qualidade e expectativas requeridas pelos clientes. 


\section{INTRODUÇÃO}

Com o foco de proteger o mercado de competidores estrangeiros e forçar a modernização dos veículos, o governo aplicou a partir de janeiro de 2013 uma série de politicas industriais e fiscais chamadas de Inovar-Auto. Uma das etapas tem como objetivo aumentar a eficiência energética dos veículos brasileiros, ligado principalmente ao consumo de combustível. O objetivo é reduzir, até 2016, em $12 \%$ o consumo médio de cada montadora ${ }_{(1)}$ e poder usufruir da isenção de $30 \%$ do IPI já a partir de 2013. Para aquelas que não alcançarem esta redução, o governo cobrará o valor integral da isenção praticada a partir deste período.

O consumo médio é medido através da massa média, em ordem de marcha, de todos os veículos comercializados no Brasil pela empresa habilitada, ponderada pelas vendas ocorridas no período de 12 meses. Para incentivar a aplicação de alternativas mais eficientes, o governo estabeleceu que para aquelas que reduzirem $15,6 \%$ do consumo terão o beneficio de redução em 1\% adicional do IPI a partir de 2017 e para aquelas que atingirem 18,8\% terão reduzido $2 \%$ deste imposto.

A redução do consumo de combustível, segundo pesquisa da $\mathrm{KPMG}_{(2)}$, é percebida por $92 \%$ dos clientes como um motivo prioritário de compra. As montadoras desenvolvem motores e versões de veículos para atender estas demandas com a intenção de melhorar a sua imagem e também se tornar competitiva no mercado. Para atingir os niveis de consumo de combustivel estabelecidos, os novos lançamentos de motores, principalmente na Europa, integram tecnologias de downsizing (redução do volume do motor com aumento da eficiencia e performance) e sistemas de Stop \& Start. No mercado brasileiro é possível encontrar alguns veículos com propósitos claros de redução de consumo, como os motores três cilindros e um litro encontrados no Volkswagen Fox Bluemotion, UP! e Hyundai HB20.

Estes sistemas Stop \& Start, atualmente disponíveis no mercado brasileiro somente para veículos de alta gama, tendem a ser um equipamento de aplicação mais ampla devido as suas características de funcionamento, de ganho efetivo em consumo e do custo associado.

Uma segunda regulamentação a considerar é a redução de dos níveis máximos de emissão de poluentes a partir de 2017. Atualmente muitas empresas estudam a possibilidade de integrarem o sistema de aquecimento de combustível, pois este melhora significativamente a combustão a baixas temperaturas, reduzindo a quantidade de gases poluentes. Outra particularidade para este sistema é atender a demanda dos clientes brasileiros para melhorar o funcionamento durante a partida a frio e dirigibilidade. Atualmente estes sistemas são aplicados em versões das montadoras Peugeot, Citroen, Honda, Volkswagen, Toyota e Ford. Por se tratar de um sistema bastante intrusivo na lógica de funcionamento do motor e também compartilhar alguns sensores do veículo, torna-se importante garantir uma interface segura entre este novo sistema e os demais já existentes. 


\section{DESCRIÇÃO DE SISTEMAS}

Em serie de 2007 na Europa, os sistemas Stop \& Start tem aumentado a sua participação no mercado automotivo mundial. Por possibilitar redução de consumo (3) (de 5\% a 10\%), com modificações no veículo a um custo relativamente baixo, as montadoras tem considerado esta solução para atingir as futuras exigências regulamentares.

O sistema consiste de um motor de partida reforçado para atender as múltiplas partidas executadas (aumento em cinco vezes em relação a um sistema normal). No entanto, para assegurar diversas condições de uso, segurança e conforto ao cliente, vários componentes são necessários como o sensor de direção, sensor de medição da corrente de bateria e o sensor depressão servo-freio.

Uma arquitetura eletroeletrônica multiplexada é especialmente utilizada como o objetivo de compartilhar as muitas informações compartilhadas entre eles.

Os principais componentes são:

Centrais de comando

1. Unidade de controle Motor $(E C M)$

2. Unidade de controle habitáculo $(B C M)$

Sensores

1. Sensor de depressão servo-freio (Mastervac)

2. Sensor de pedal de embreagem (Clutch $V B$ )

3. Botão Stop \& Start $(S \& S$ switch and led)

4. Sensor de temperatura externa (external temperature)

Contatos simples

1. Contato de abertura da tampa do motor (Hood)

2. Contato de porta passageiro (Doors)

3. Contato do cinto de segurança (Seatbelt)

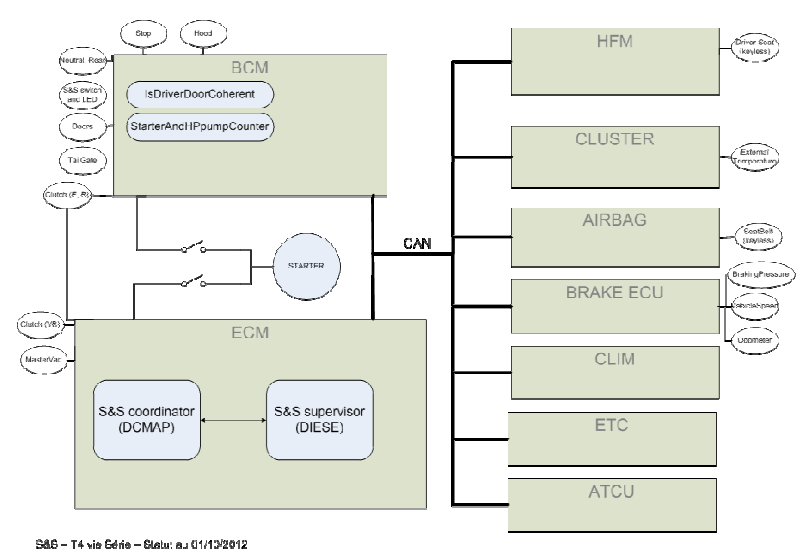

Fgura 1 - Esquemático do Sistema Stop\&Start 
O princípio de funcionamento consiste na parada do motor automaticamente no momento que as condições de condução permitam (marcha em ponto morto, pedal da embreagem liberado e velocidade próxima de zero) e realizar a repartida quando o condutor solicita-lo (por exemplo, ao apoiar o pé novamente na embreagem ou movimentar a direção). Podemos também ter a condição que o sistema execute novamente a partida na situação de falta de pressão no servofreio dos freios ou a bateria em baixa carga (repartida técnica).

Em algumas situações o sistema não é habilitado a funcionar, para preservar o conforto térmico, carga da bateria, boas condições de partida de motor, entre outras.

No desenvolvimento destes sistemas, várias condições de uso cliente são testadas e validadas, com o foco em satisfazer as expectativas do cliente, como comportamento na partida, conforto térmico e ganho em consumo. Para equilibrar estas demandas, os engenheiros desenvolvem modelos de funcionamento estático e dinâmico e, junto com especialistas em Software, trazem para o mundo virtual as diferentes condições de uso. O sistema é então ensaiado em profundidade em diferentes condições de uso normal e também em situações extremas.

Uma das dificuldades na adaptação deste sistema no mercado brasileiro é o funcionamento com o sistema de flexível de combustível (mistura de gasolina e etanol).

O sistema de aquecimento de combustível foi concebido para aumentar o conforto ao cliente (eliminação da necessidade de repor gasolina no tanque auxiliar) e em alguns casos reduzir o nível de emissões. Eles utilizam resistências instaladas no circuito de combustível próximo ao motor (galeria ou injetores) que são acionadas em condições de baixa temperatura. Por se tratar de um modo de operação bastante específico, existem sistemas de identificação de mistura de combustível integrado no controlador de aquecimento para liberar a corrente para as resistências somente quando se reconhece o álcool. Outra particularidade é a compensação da potência permitida por este módulo devido às variações de tensão no sistema elétrico do veículo (carga da bateria e envelhecimento de componentes). Para que a correta potência seja liberada em função da temperatura de combustível, existe um modelo de temperatura integrado no controle de motor o qual procura manter uma variação mínima entre o valor calculado e o valor de temperatura modelado pela corrente circulante nas resistências de aquecimento. 


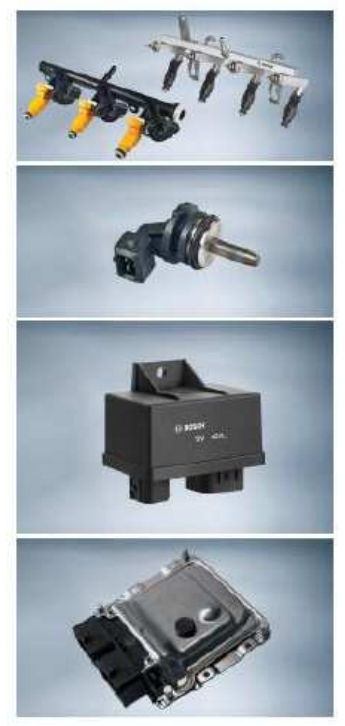

Figura 2 - Sistema Flex Start [Bosch] [4]

\section{Interconexão sistemas S\&S e Aquecimento de Combustivel}

Mesmo que os dois sistemas são concebidos para realizar diferentes funções, é necessário termos uma analise do funcionamento em situações de uso cliente. Estas são hipóteses que necessitam ser analisadas mais profundamente pelos especialistas durante o desenvolvimento.

Condição 1 - mudança ou variação na mistura de combustível principal ou perda da informação sobre conteúdo de álcool no combustível. Durante a fase de reconhecimento do combustível, que acontece principalmente durante a marcha-lenta, o sistema Stop \& Start não pode permitir uma parada do motor voluntariamente, pois ocasionará uma interrupção do processo de reconhecimento e consequências no funcionamento normal.

Condição 2 - avaliação do impacto de partidas nos componentes. Uma vez que a aplicação do sistema Stop \& Start pode ocasionar uma série de partidas e paradas do motor em condições de aquecimento, devido ao enriquecimento necessário para partir em álcool, isto pode impactar a lubrificação dos cilindros, ao envelhecimento precoce do óleo do motor e também a formação de resíduos internos no motor. Devem ser feitos provas de durabilidade para conter estas condições de trabalho.

Condição 3 - aumento da quantidade de álcool no óleo. Um dos efeitos indesejados da diluição do álcool no óleo é a vaporização do álcool quando temperaturas superiores a $65^{\circ} \mathrm{C}$ ocorrerem, durante a fase de inicio do blow-by. Nesta condição, modelada através de cálculos internos do controle motor, a aprendizagem de combustível é bloqueada e somente liberada quando esta fase de vaporização for reduzida. Se a quantidade de álcool no óleo aumentar muito, isto pode significar que a fase de aprendizagem será mais longa e isto pode ter impacto nas prestações de dirigibilidade e partida a frio. 
Condição 4 - mudança da condição do botão de acionamento do Stop \& Start pelo condutor. Durante a fase de aquecimento do motor e também do combustível o condutor pode acionar o do sistema Stop \& Start. Deverá existir uma priorização entre o sistema Stop \& Start e de aquecimento para estabelecer a condição mais apropriada ao funcionamento. Isto é particularmente importante durante os ensaios de emissões usados para as homologações.

Condição 5 - situação quando o motor para de forma repentina. Nesta condição, o pedal de embreagem ao ser pressionado, o sistema Stop \& Start autorizará uma nova partida. Se isto acontecer durante a fase de aquecimento do combustível, poderemos ter uma partida ruim ou uma pane.

Condição 6 - diagnose do sistema. Para que os modos de falha sejam bem identificados pelas ferramentas de diagnose, as estratégias de identificação de problemas devem evoluir para permitir que a rede de assistência técnica possa resolver os problemas rapidamente.

Condição 7 - homologação de funcionamento OBD (on-board diagnose). Com a evolução dos sistemas de diagnose embarcados, as avaliações de funcionamento correto de componentes são mais complexas (sonda de oxigênio, taxa de conversão catalítica, falha de ignição). Por isso, com a coabitação dos sistemas é necessário rever o funcionamento destas diagnoses.

\section{FUTURAS EVOLUÇÕES}

Como as politicas de redução de combustível e emissões de poluentes devem continuar a serem promovidas pelos agentes governamentais, é muito importante trabalhar de forma antecipada focando na redução do custo e melhoria da funcionalidade e qualidade.

Os módulos eletrônicos compartilham informações de funcionamento entre eles para garantir que as ações sejam coordenadas e bem executadas. Os sistemas Stop \& Start e controle de aquecimento de combustível poderão no futuro estarem integrados num mesmo modulo de controle e assim reduzir os custos. Podemos considerar que a unidade controle de habitáculo ou gestão de energia possa conservar a função de controle de aquecimento.

Outra possibilidade é a incorporação da informação do sensor de corrente consumida, presente no sistema Stop \& Start, para o sistema de controle de aquecimento de combustível. Desta maneira as condições de funcionamento podem ser aprimoradas e melhor diagnosticadas para cada aquecedor.

\section{CONCLUSÃO}

Este estudo demonstrou que com o advento dos sistemas de aquecimento de combustível e Stop \& Start no mercado brasileiro são necessárias adaptações de controle de funcionamento 
entre os mesmos. As condições de uso cliente devem ser profundamente avaliadas e validadas durante o desenvolvimento e assim prover produtos com boas funcionalidades atendendo as expectativas dos clientes.

\section{REFERENCIAS}

[1] CAlCAgnotTo, Antonio, Workshop Inovar - Auto. Novo Regime Automotivo Brasileiro, 2013

[2] MEYER, Mathieu, Global Automotive Executive Survey KPMG International 2013 [3] KREMER, Markus, In-market Application of Start - Stop Systems in European market 2011

[4] Bosch Brasil, http://www.bosch.com.br/sustentabilidade/atualidades-noticias-201210.aspx, acessado 22/5/2014, 18h00. 